\title{
A comparison of three tests for rubella antibody screening
}

\author{
P. MORGAN-CAPNER ${ }^{1}$, HAZEL J. M. PULLEN 1 , J. R. PATTISON ${ }^{1}$, \\ D. E. BIDWELL ${ }^{2}$, ANN BARTLETT2, AND A. VOLLER ${ }^{2}$
}

From the ${ }^{1}$ Department of Microbiology, King's College Hospital, Denmark Hill, London SE5 and the 2 Institute of Zoology, Nuffield Laboratories of Comparative Medicine, Zoological Society of London, Regents Park, London NWI, UK

SUMMARY Sera from 1000 women attending antenatal clinics were screened for the presence of rubella antibody by haemagglutination-inhibition (HI), single radial haemolysis (SRH), and enzymelinked immunosorbent assay (ELISA). With 925 sera concordant results were obtained with all three tests. There were 46 false-negative $\mathrm{HI}$ tests due to the necessity of allowing for residual nonspecific inhibitors. With SRH there was one false positive and three that were negative by SRH but HI- and ELISA-positive. By ELISA 14 sera gave a false-positive result (OD $405 \mathrm{~nm}>0 \cdot 2$ ). Ten of these could be eliminated by taking an OD $405 \mathrm{~nm}$ of 0.5 as the threshold but then another 10 sera became false negatives.

The screening of adult women for the presence of rubella antibodies forms a substantial commitment for clinical virology laboratories. The demand for this service is increasing to include groups such as those attending family planning clinics in addition to those at occupational risk or who are pregnant. Up to now the haemagglutination-inhibition (HI) test has been used for rubella antibody screening but it is relatively labour-intensive, requiring careful control.

It has been suggested that single radial haemolysis (SRH) and enzyme-linked immunosorbent assay (ELISA) would offer considerable advantages (Voller and Bidwell, 1975; Russell et al., 1978).

In this study we have evaluated the ability of the three techniques to determine immunity to rubella in 1000 consecutive antenatal patients.

\section{Material and methods}

SERA

One thousand consecutive sera submitted for rubella screening from antenatal patients in south-east London were evaluated. Sera were stored at $-20^{\circ} \mathrm{C}$ before testing.

SRH TECHNIQUE

The SRH plates were provided by Wellcome Research Laboratories Ltd, Beckenham, Kent.

Received for publication 5 December 1978
They were prepared and used according to Russell et al. (1978). In the laboratory, plates were stored at $4^{\circ} \mathrm{C}$ and used within 14 days of receipt. Sera were inactivated at $56^{\circ} \mathrm{C}$ for 30 minutes before the $3 \mathrm{~mm}$ diameter wells were filled with disposable microcapillary tubes. The sera were allowed to diffuse overnight at $4^{\circ} \mathrm{C}$ in a humidified atmosphere before flooding with a 1:10 dilution of guinea-pig complement (LIP Ltd, Shipley, Yorks) and incubation for a further 3 hours at $37^{\circ} \mathrm{C}$. Zones of haemolysis were measured with a calibrated eyepiece (Flubacher \& Co) against an illuminated background.

All sera gave a small ring of complete clearing, $3.5 \mathrm{~mm}$ in diameter. Zones of haemolysis between 3.5 and $5 \mathrm{~mm}$ in diameter were often indistinct. Therefore, zone diameters $>5 \mathrm{~mm}$ were taken to indicate immunity. Sera that gave results discordant with the HI and ELISA tests were retested and also tested in control plates containing unsensitised sheep red blood cells.

\section{HI TECHNIQUE}

Non-specific inhibitors of rubella haemagglutination (HA) were removed by treatment with manganous chloride/heparin mixture (Plotkin et al., 1968). The rubella $\mathrm{HI}$ test incorporated $8 \mathrm{HA}$ units of antigen (Central Public Health Laboratory, Colindale, London) and a serum/antigen incubation of 1 hour at room temperature before the addition of day-old chick red blood cells (Sera-lab, Crawley, Sussex). Results were reported in international units by 
comparison with a reference positive control serum (Central Public Health Laboratory, Colindale). The presence of 25 or more units of rubella $\mathrm{HI}$ antibody was taken to indicate immunity.

Sera giving discordant results compared with SRH and ELISA were retested as above and also after removal of non-specific inhibitors with kaolin (Stewart et al., 1967). Seventeen sera gave an HI titre of $<6$ units with the $\mathrm{MnCl}_{2}$ /heparin method and an HI titre of 6 or 12 units with the kaolin method since with some sera $\mathrm{MnCl}_{2}$ /heparin enhances non-specific agglutination, and this can obscure the presence of low-titre antibody (Doherty et al., 1975).

\section{ELISA TECHNIQUE}

The technique was based on that of Voller and Bidwell (1975) using unit volumes of $200 \mu$ l. Antigen for the ELISA test was prepared by Tween/ether extraction of rubella virus-infected baby hamster kidney cells. The HA titre of this preparation was 1024. Control antigen was similarly prepared from uninfected cells. Rubella HA antigen and its control antigen were diluted in $0.05 \mathrm{M}$ sodium carbonate buffer, pH 9.6, equivalent to a titre of 1-2 HA units, and allowed to coat the wells of flat-bottomed polystyrene plates (M29AR Dynatech Laboratories, Billingshurst, Sussex) for 2 hours at $4^{\circ} \mathrm{C}$. The plates were washed in phosphate-buffered saline (PBS) containing $0.05 \%$ Tween 20 (PBS/T20).

Test sera diluted 1 in 200 in PBS/T20 were reacted in the wells for 3 hours at room temperature. After washing, a volume of anti-human IgG (Dako Laboratories, Copenhagen, Denmark) conjugated to alkaline phosphatase (Sigma Chemical Corp Ltd) was added, and the plates were held overnight at $4^{\circ} \mathrm{C}$. After further washing, para-nitrophenylphosphate $(1 \mathrm{mg} / \mathrm{ml}$ in $1 \mathrm{M}$ diethanolamine buffer, pH 9.8) was added, and the reaction was allowed to proceed at room temperature. The reaction was stopped with $50 \mu 13 \mathrm{M} \mathrm{NaOH}$ when a reference positive serum, included in each plate, had achieved an OD $405 \mathrm{~nm}$ of 1.0 . All results were read photometrically at $405 \mathrm{~nm}$. All sera were tested in duplicate with the rubella antigen and singly against the control antigen. Any reaction with the latter was subtracted from the reaction obtained with the serum against the rubella antigen. Sera that gave a photometer reading of $\mathbf{0 . 2}$ or greater were regarded as positive.

\section{Results}

Nine hundred and twenty-five sera gave concordant results in all three screening tests; 805 were positive and 120 were negative (Table 1). Two of these 120
Table 1 Results of 1000 sera tested by HI, SRH, and ELISA

\begin{tabular}{llll}
\hline Number & \multicolumn{3}{l}{ Rubella antibody by: } \\
\cline { 2 - 4 } & HI & SRH & ELISA \\
\hline 805 & + & + & + \\
120 & - & - & - \\
46 & - & + & + \\
7 & + & - & + \\
1 & - & + & - \\
21 & - & - & + \\
\hline
\end{tabular}

$+>24$ units by $\mathrm{HI},>5.0 \mathrm{~mm}$ zone diameter by $\mathrm{SRH}$, and an OD. $405 \mathrm{~nm}$ of $>\mathbf{0 . 2}$ in the ELISA test.

$-\gtrless 24$ units (HI), $<5.0 \mathrm{~mm}$ (SRH), and $<0.2$ (ELISA).

Table 2 Analysis of 46 sera that gave results indicating susceptibility by HI but immunity by $S R H$ and ELISA

\begin{tabular}{|c|c|c|c|c|c|c|}
\hline \multirow[t]{3}{*}{ Number } & \multicolumn{6}{|c|}{ Rubella antibody by: } \\
\hline & \multicolumn{2}{|c|}{ HI (units) } & \multicolumn{2}{|c|}{$S R H(m m$ diam $)$} & \multicolumn{2}{|c|}{ ELISA $(O D 405 \mathrm{~nm})$} \\
\hline & 6 & 12 & $<5.0$ & $>5.0$ & $0.2-0.5$ & $>0.5$ \\
\hline 5 & + & & & + & + & \\
\hline 2 & + & & & + & & + \\
\hline $\begin{array}{r}4 \\
35\end{array}$ & & + & & + & + & $\perp$ \\
\hline 35 & & + & & + & & + \\
\hline
\end{tabular}

sera contained 12 units of $\mathrm{HI}$ antibody. The remaining 118 contained $<6$ units of $\mathrm{HI}$ antibody. Using the screening criteria defined in Material and methods, 46 sera were $\mathrm{HI}$ negative but positive by SRH and ELISA (Table 1). All 46 of these sera had detectable $\mathrm{HI}$ antibody, 6 units in seven sera, and 12 units in 39 sera (Table 2). All 46 sera gave SRH zones greater than $5 \mathrm{~mm}$ in diameter, nine gave ELISA readings of $0 \cdot 2-0 \cdot 5$, and 37 gave readings of greater than $0 \cdot 5$.

Seven sera were initially judged to be negative by SRH and positive by HI and ELISA. One of these sera gave no zone in the SRH plate, but with the remaining six a small zone in the SRH plate (3.5-5.0 $\mathrm{mm}$ diameter) was found. There were five other sera that gave a SRH zone of $3.5-5.0 \mathrm{~mm}$; all five had detectable $\mathrm{HI}$ antibody (6 $\mathrm{U}$ and $12 \mathrm{U}$ ) and a positive ELISA reading (Table 3 ). With one serum a zone of $8.5 \mathrm{~mm}$ diameter was found by SRH but no rubella antibody was detectable by HI or ELISA (Table 1). This serum also gave a zone $(7 \mathrm{~mm}$ diameter) in a control SRH plate and had a sheep red blood cell agglutinin titre of 320 .

Twenty-one sera were ELISA positive and SRH and $\mathrm{HI}$ negative by the original criteria for screening. Fourteen (Table 3, categories a and b) of these had no detectable rubella antibody by HI and SRH 
Table 3 Further analysis of 21 sera that were rubella antibody positive by ELISA but negative by $S R H$ and $H I$ by the original screening criteria

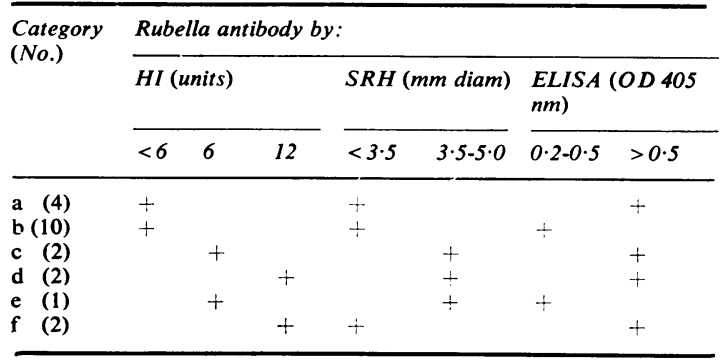

but gave ELISA readings of 0.5 or greater (4 sera) or $0 \cdot 2-0 \cdot 5$ (10 sera). Five sera (Table 3, categories $\mathrm{c}, \mathrm{d}$, and $\mathrm{e}$ ) with a positive ELISA reading $(0 \cdot 2-0 \cdot 5$ with 1 and 0.5 or greater with 4) contained detectable rubella $\mathrm{HI}$ antibody (6 or $12 \mathrm{U}$ ) and gave a small zone (3.5-5.0 $\mathrm{mm}$ diameter) in the SRH plates. The remaining two sera (Table 3, category $f$ ) gave an ELISA reading of greater than $0 \cdot 5$, contained 12 units of rubella antibody, but gave no zone in SRH. In the 1000 sera tested, only 21 gave ELISA readings of $0 \cdot 2-0 \cdot 5$. Of these, 10 contained detectable rubella antibody by HI and SRH (Tables 2 and 3), one contained HI antibody but gave no zone in SRH plates, and 10 had no rubella antibody detectable by HI or SRH (Table 3).

\section{Discussion}

With 925 out of the 1000 sera tested, concordant results were obtained. With these sera an unequivocal, easily read positive or negative result was obtained in each of the three tests. The largest group of discordant results consisted of 46 sera that were screened as HI negative, SRH and ELISA positive. When using the HI test for rubella antibody screening, the possible occurrence of residual nonspecific inhibitors is well recognised. To avoid these being interpreted as specific antibody, indicating immunity, the minimum immune titre is usually taken as one or two dilutions higher than the minimum detectable antibody titre. An acceptable minimum immune titre is 20-24 units of rubella $\mathrm{HI}$ antibody (Bradstreet et al., 1978). However, it is clear that the majority of sera with small amounts of detectable rubella $\mathrm{HI}$ activity (5-20 U) do contain specific antibody. In the present series, 46 sera with 6 or 12 units of rubella $\mathrm{HI}$ activity contained rubella antibody by SRH and ELISA, but two sera with 12 units by HI were negative by the other tests. Thus, using a minimum immune titre of 24 units, none of the 1000 sera tested gave a false-positive result but 46 sera that contained rubella antibody would be reported as seronegative on the basis of the HI screening test. If a minimum immune titre of 12 units had been used the number of false negatives would fall to seven but there would also be two false-positive $\mathrm{HI}$ antibody results.

Initially, we regarded SRH zones of $3.5-5.0 \mathrm{~mm}$ diameter as equivocal since we found these indistinct and difficult to read compared with the zones of $>5.0 \mathrm{~mm}$ in diameter. However, experience showed that all 11 sera (Table 1 and Table 3, categories c, d, e) with such small zones contained rubella antibody by HI and ELISA. Therefore, it is concluded that these specimens can be regarded as seropositive, and, if so, there were only three sera (Table 1 and Table 3, category f) that were SRH negative but HI and ELISA positive. This pattern of reactivity is found in sera containing rheumatoid factor (Gee et al., 1978; Russell et al., 1978), but insufficient remained to test the sera from this series for rheumatoid factor.

With the SRH test one serum gave a false-positive result which would be detected only if the sera were tested in a control as well as a test SRH plate. The serum had a sheep red blood cell agglutinin titre of 320 , but insufficient remained for any further testing. An occasional serum giving similar results has been described previously (Grillner and Strannegård, 1976; Gee et al., 1978), but no satisfactory explanation is known. Such false-positive SRH results do not correlate with the Paul Bunnell titre (Russell et al., 1978).

Using an optical density reading of 0.2 or greater to indicate the presence of specific rubella antibody, ELISA did not give any false-negative results, but there were 14 sera that were ELISA positive but which had no detectable rubella antibody by $\mathrm{HI}$ or SRH. If an optical density reading of 0.5 or greater was used to define immunity, only four of these sera would have been considered positive. However, this would result in 10 sera being labelled ELISA negative which contained HI and SRH antibody. Only one serum gave a significant reaction with the control antigen. Subtraction of this absorbance value from that obtained against the test antigen still indicated that the serum contained antibody to rubella virus.

Screening for rubella antibodies using an HI test results in $4.6 \%$ false negatives but no false positives. Thus false positives are completely avoided at the expense of 46 unnecessary doses of vaccine per 1000 women tested. In the SRH plates, sera give a very small ring of complete clearing, which must be ignored since it does not represent specific antibody. However, if any zone of haemolysis other than this 
is taken to indicate the presence of specific antibody, the SRH test results in $0.3 \%$ false negatives and $0.1 \%$ false positives. No satisfactory method is known for eliminating the former, and the latter can be detected only by testing the sera in control plates. Thus, one woman in every thousand would remain unprotected and three unnecessary vaccinations would be given.

With ELISA there were either $1.4 \%$ false positives or $0.4 \%$ false positives plus $1.0 \%$ false negatives, depending on the value used to indicate immunity. It is possible that the four women whose sera gave an ELISA reading of greater than 0.5 but were $\mathrm{HI}$ and SRH negative are immune to rubella since there are a few individuals who have no detectable $\mathrm{HI}$ antibody but who do not have an antibody response to repeated doses of rubella vaccine (Pattison, unpublished observations). However, if they are false positives, then using the ELISA test, four susceptible women per thousand would not be offered vaccine after testing and 10 unnecessary doses of vaccine per thousand women tested would be given.

We thank Wellcome Research Laboratories Ltd for providing the SRH plates and Philip Turp for technical assistance.

\section{References}

Bradstreet, C. M. P., Kirkwood, B., Pattison, J. R., and Tobin, J. O'H. (1978). The derivation of a minimum immune titre of rubella haemagglutination-inhibition
HI antibody. A Public Health Laboratory Service collaborative survey. Journal of Hygiene (Camb.), 81, 383-388.

Doherty, N., Ronalds, C. J., Pattison, J. R., and Heath, R. B. (1975). A comparative study of methods used for removing non-specific inhibitors of rubella haemagglutination from human sera. Medical Laboratory Technology, 32, 317-320.

Gee, B.. Jordan, B. E., and Mortimer, P. R. (1978). An assessment of radial haemolysis in the detection of rubella antibody. Journal of Clinical Pathology, 31, 35-38.

Grillner, L., and Strannegård, O. (1976). Evaluation of the hemolysis-in-gel test for the screening of rubella immunity and the demonstration of recent infection. Journal of Clinical Microbiology, 3, 86-90.

Plotkin, S. A., Bechtel, D. J., and Sedwick, W. D. (1968). A simple method for removal of rubella haemagglutination inhibitors from serum adaptable to finger-tip blood. American Journal of Epidemiology, 88, 301-304.

Russell, S. M., Benjamin, S. R., Briggs, M., Jenkins, M., Mortimer, P. P., and Payne, S. B. (1978). Evaluation of the single radial haemolysis (SRH) technique for rubella antibody measurement. Journal of Clinical Pathology, 31, 521-526.

Stewart, G. L., Parkman, P. D., Hopps, H. E., Douglas, R. D., Hamilton, J. P., and Meyer, H. M., Jr. (1967). Rubella-virus haemagglutination-inhibition test. New England Journal of Medicine, 276, 554-557.

Voller, A., and Bidwell, D. E. (1975). A simple method for detecting antibodies to rubella. British Journal of Experimental Pathology, 56, 338-339.

Requests for reprints to: Dr P. Morgan-Capner, Department of Medical Microbiology, King's College Hospital Medical School, Denmark Hill, London SE5 8RX, UK. 